\title{
Patient Satisfaction Evaluation in CGHS Dispensaries in Kolkata, India
}

\author{
Amitabha Chattopadhyay ${ }^{1}$, TusharKanti Saha ${ }^{2}$, PrasantoRay Karmakar ${ }^{3}$, \\ Prajjal Sengupta ${ }^{4}$,Kakoli Boral ${ }^{5}$, Shamima Yasmin ${ }^{6}$ \\ 1,(Assistant Professor, Department of Community Medicine,R.G.Kar Medical College, West Bengal, India) \\ 2(Assistant Professor, Department of Community Medicine, NRS Medical College, West Bengal, India) \\ 3,(Associate Professor, Department of Community Medicine,R.G.Kar Medical College, West Bengal, India) \\ 4,5(Assistant Professor, Department of Community Medicine, NRS Medical College, West Bengal, India) \\ 6(Demonstrator, Department of Community Medicine, NRS Medical College ,West Bengal, India)
}

\begin{abstract}
Background: Patient satisfaction is one of the important studied aspects of health care. Measuring satisfaction reliably, however, is an ongoing challenge, thus objective of the study was to assess patient satisfaction in CGHS Dispensaries. Methodology: This cross sectional study was conducted over one year period in CGHS Dispensaries at Kolkata. A multistage sampling method was followed. Total number of respondents was 412. A self administered predesigned, pretested, semi structured questionnaire was used. Likert scale was used as scoring system in the questionnaire for patient satisfaction evaluation. Results: The overall level of satisfaction( moderate \& very satisfied)in this study was 36.9\%. Majority of the total respondents (84\%) agreed/strongly agreed regarding the inadequacy of facilities like toilet, drinking water, sitting arrangement in the dispensaries. About (72.5\%) of the overall respondents agreed/strongly agreed to the fact that doctors treating them were attentive, overwhelming majority of the total respondents (88.4\%) was of the opinion that overcrowding was a problem in the dispensaries. Statistically significant association was found between patient satisfaction and per capita income in this study.Conclusion: The overall recommendation is that CGHS should strive to maintain the standard it has in order to keep patients satisfied with the services they receive.
\end{abstract}

Keywords - CGHS Dispensaries, likert scale, patient satisfaction.

\section{Introduction}

Patient satisfaction is one of the important studied aspects of health care .It can be an especially valid indicator of quality care and measurement of patient satisfaction in the health care field has been shown to be an increasingly important determinant of overall patient outcomes ${ }^{1}$. Measuring satisfaction reliably, however, is an ongoing challenge .Individual patient attitudes, expectations, and demographics clearly influence patient satisfaction levels. Given the same quality of care, two individuals may have radically different perceptions and, thus, different satisfaction levels .

Patients perception of medical care are of increasing importance to educators, researchers and clinicians. The emphasis on patient satisfaction is consistent with the trend towards holding health professionals accountable to their consumers ${ }^{2}$. The Central Government Health Scheme was started under the Ministry of Health and Family Welfare in New Delhi in 1954 to provide comprehensive medical care to central govt. employees, based on the principles of co-operative effort by employees and employers to the mutual advantage of both.

In the face of increasing demand and resource constraints, the challenge that exists today is to reach the whole population with adequate health services and ensure their utilization. All healthcare providers and programmes in India have overwhelming emphasis on quantitative aspect of service delivered, which means that, in a quest to chase runaway targets, we neglect the concept of quality of care, which is also a right of clients $^{3}$. People's perception about quality of care often determines whether they seek and continue to use services . Being intangible in nature, the perception directly affects the quality rating in service. So, there are attempts to scale and measure this perception. Outpatient department(OPD) is the window to any health system and OPD care indicates the quality care of hospital reflected by patient's perception in terms of satisfaction to the services they are provided ${ }^{4}$ Scarcity of information on this aspect of health care inspired the researcher to carry out the present study at the Central Government Health Scheme (CGHS) Dispensaries at Kolkata, with the objective of assessing patient satisfaction regarding the quality of health care services. 


\section{Materials and Methods}

This health service research study, cross sectional in design was conducted over one year period ( May 2008- April 2009) in CGHS Dispensaries at Kolkata. The permission for conducting the study was taken from The Additional Director, CGHS, Kolkata. A multistage sampling method was followed. Dispensaries were selected by simple random sampling method using random number table. Out of 18 CGHS Dispensary at Kolkata, 5 CGHS Dispensaries (about 25\%) were selected .Patient selection was then done by systematic random sampling method. Every $5^{\text {th }}$ new patient on the day of data collection was selected. If the $5^{\text {th }}$ patient refused to participate, the next patient was taken. Total number of patients approached was 431, out of which 19(4.4\%) refused to participate. Final total number of respondents was 412. For questionnaire preparation and pretesting, one separate dispensary was selected by simple random method. Validation of the questionnaire was done in consultation with the senior faculty members of All India Institute of Hygiene and Public Health, Kolkata. Informed consent of the participants were taken; in case of respondents below $18 \mathrm{yrs}$ of age, parental consent was taken wherever available. A self administered predesigned, pretested, semi structured questionnaire(containing both open $\&$ closed ended questions) was given to the selected respondents on first contact in the dispensary and was again collected back during exit. During pretesting, it was found that children below 12 yrs of age were unable to respond to the questionnaire in satisfactory manner. Thus during the study, in case of children below 12 yrs of age $(n=14)$ the questionnaire was filled by direct face to face interview. Data was entered in MICROSOFT EXCEL 8.0 software and was analyzed with the help of EPI INFO3.4.3 to obtain the results. Likert scale was used to give scores to the responses of the 10 closed ended specific questions asked in the questionnaire for patient satisfaction evaluation.

(Strongly disagree: -2, Disagree : -1,Neither agree nor disagree : 0,Agree : 1, Strongly agree: 2) Scoring of question no 3,4,8,9,10 got reversed as they were questions with negative impact .(Table-1)Total score of all individual 412 patients were calculated, mean score of each patient was calculated, total sample mean was calculated, individual $\mathrm{Z}$ score of individual patients were found out. Thereafter $\mathrm{Z}$ scores were arranged in descending order and divided into quartiles. The 4 segments were classified accordingly as -

\begin{tabular}{|l|l|l|l|}
\hline very unsatisfied & $\begin{array}{l}\text { moderately } \\
\text { unsatisfied }\end{array}$ & $\begin{array}{l}\text { moderately } \\
\text { satisfied }\end{array}$ & very satisfied \\
\hline
\end{tabular}

These 4 segments were thereafter used for patient satisfaction categorization. Chi square test was used(taking $\mathrm{p}$ $\leq 0.05$ as the statistically significant level ) to find out if any association existed between the level of satisfaction and different attributes.

\section{Results}

Table 1 enlist the 10 closed ended questions given to the respondents and their responses. This table showed that about $65.3 \%$ of the total respondents strongly agreed/ agreed to the statement that general medical services was satisfactory in the dispensaries. $74.7 \%$ of the total respondents strongly agreed/ agreed to the statement that adequate medical supply was present in the dispensaries. Majority of the total respondents(84\%) agreed/strongly agreed regarding the inadequacy of facilities like toilet, drinking water, sitting arrangement in the dispensaries $.38 .8 \%$ of the total respondents gave affirmative responses regarding the lab services being unsatisfactory, while only $9 \%$ of the total respondents were absolutely satisfied regarding the lab services(Fig. 1). About (72.5\%) of the overall respondents agreed/strongly agreed to the fact that doctors treating them were attentive and sympathetic (Fig. 2)while less than $50 \%$ of the total respondents $(46.6 \%)$ were satisfied with the doctors punctuality in maintaining outdoor activities. $52.5 \%$ of the total respondents felt that the dispensaries were not located near to their home; overwhelming majority of the total respondents $(88.4 \%)$ was of the opinion that overcrowding was a problem in the dispensaries. $68.7 \%$ of the total respondents felt that the number of doctors in the dispensaries was inadequate while $54.7 \%$ of the total respondents were of the opinion that outdoor hours should be increased.

Table 2 shows the distribution of the respondents on the basis of the different levels of satisfaction. Satisfaction level of CGHS respondents were divided into 4 categories- very unsatisfied, moderately unsatisfied, moderately satisfied, very satisfied. This was done on the basis of $\mathrm{z}$ scores of the respondents after being arranged in quartiles. Highest $\%$ of respondents belonged to the first quartile(moderately unsatisfied) while lowest $\%$ was that in the $3^{\text {rd }}$ quartile(very satisfied)(Fig 3).

Distribution of the level of satisfaction according to different attributes of the participants is depicted in Table 3. This table shows that $\%$ of very unsatisfied respondents was more among females than in males(22.9\% vs 20.7\%), while overall satisfied respondents were almost equal in both gender. Among Government employees \& dependents, $59.3 \%$ of the respondents were unsatisfied, while among Pensioners $(\%)$ $\&$ dependents category $70.4 \%$ of the respondents were unsatisfied, but the highest percentage of dissatisfaction was among the respondents who belonged to the category of Freedom fighters \& others $(\%) \&$ 
dependents $(85.7 \%)$. Per capita income category of $\leq$ Rs. 9000 but $>$ Rs. 6000 had $48.06 \%$ of respondents who were moderately satisfied/very satisfied, while pci category of $\leq$ Rs.3000 had $74.82 \%$ of respondents who were moderately unsatisfied/very unsatisfied; statistically significant association was found between per capita income and level of satisfaction of the respondents. Age group of $\leq 60 \mathrm{yrs}$ but $>40 \mathrm{yrs}$ had highest $\%$ of moderately satisfied/very satisfied respondents(43.6\%), while age group of $>60 \mathrm{yrs}$ had highest $\%$ of moderately unsatisfied/very unsatisfied respondents $(69.1 \%)$;however any association between different age groups and level of satisfaction was not found.

\section{Discussion}

The goal of any service organization is creation of satisfaction among the customers. The Maslow's theory of hierarchy of needs is famous theory which says that man is wanting animal and his motives go on changing. The fulfilled motive no longer remains a motive, once one's need is fulfilled the other takes the place 5 . The concept of patient satisfaction is rapidly changing to customer's delight which means the patient is not only cured of his ailments but is also pleased with the amenities provided to him by the organization and its staff. The role of manpower does play a very important role in patient satisfaction. A medical institute is a complex organization and every person directly or indirectly involved in rendering services is important for the patient ${ }^{6}$. The modern treatment based on advance technology is not only costly but is full of complexities. Therefore patient satisfaction has a special consideration in treatment.

To mention a few important research works in relation to patient satisfaction carried out in India, a reference can be made to Srivastava R.K. e.tal who carried out a cross sectional study on utilization of $\mathrm{RCH}$ services and client satisfaction during October to December 2008 at two selected blocks of Varanasi district on 509 women selected through a multistage sampling technique ${ }^{7}$. The study found that $16.3 \%$ of the respondents, irrespective of social category, educational status and occupation were not satisfied with the services provided by government health facilities. About $44 \%$ found services 'just satisfactory' followed by $26.7 \%$ who found it 'satisfactory' and only $6.5 \%$ found it 'most satisfactory'. A cross-sectional study was conducted to determine the level of patient's satisfaction with hospital care in Regional Institute of Medical Sciences, Imphal among patients during the month of May $2007^{8}$.Most of the patients $(74.1 \%)$ were satisfied with the overall care received. A patient satisfaction survey was conducted in 25 District or Area Hospitals managed by the Andhra Pradesh Vaidya Vidhana Parishad (APVVP) ${ }^{9}$.Overall, the level of patient satisfaction in APVVP was about $65 \%$. In, comparison, the overall level of satisfaction( moderate \& very satisfied)in this study was about $36.9 \%$.

A study carried out from May2006 to August 2006 in the outpatient department (OPD) of government health facilities of Lucknow district ${ }^{10}$ reported that accessibility was difficult in $42 \%$ patients and $64.6 \%$ of the patients were satisfied with the duration of the outpatient department (OPD). $52.5 \%$ of the total respondents of our study felt that the dispensaries were far away from their home while $54.7 \%$ of the total respondents were of the opinion that outdoor hours should be increased.

A cross sectional study was conducted at Jimma Hospital, Ethiopia, from November to February1999 by Oljira L, Gebree-Selassie S ${ }^{11}$.A total of 385 outpatients, females were interviewed at exit of hospital. Overall, $57.1 \%$ of interviewee believed that the service they received was either good or very good. Satisfaction with healthcare was found to have a direct relationship with increase of age but had an inverse relation with increase in educational level of the respondents. A cross sectional study conducted on 299 patients visiting outpatient department (OPD) of Dhaka Medical College Hospital (DMCH) between November 2005 and April 2006 (6 months) reported that majority of the patients $(81.14 \%$ ) expressed satisfaction (ranging from fair to good) with respect to adequacy of space, sitting arrangement and cleanliness of the waiting rooms, but were dissatisfied $\left(75.31 \%\right.$ ) with respect to toilet facilities and supply of drinking water ${ }^{12}$. In our study, $36.7 \%$ of the beneficiaries were satisfied regarding the laboratory services, while $59.75 \%$ of the patients held similar view regarding laboratory services in the study conducted at Dhaka Medical College Hospital (DMCH) ${ }^{12 .}$ In the $(\mathrm{DMCH})$ study, women were more satisfied with OPD services compared to their male counterparts

$(\chi 2, \mathrm{p}<0.05)$ and patient's satisfaction was found to be inversely related to monthly income $(\chi 2, \mathrm{p}<0.05)$ and level of education $(\chi 2, p<0.05)$. Statistically significant association was found between patient satisfaction and per capita income in our study but no association was found with different dispensaries, gender, category of benefit holders and age.

\section{Conclusion}

The quality of service in health means an inexpensive type of service with minimum side effects that can cure or relieve the health problems of the patients. It is easier to evaluate the patient's satisfaction towards the service than evaluate the quality of medical services that they receive. Therefore, a research on patient satisfaction can be an important tool to improve the quality of services. 
Item wise ,in our study there was satisfaction regarding the general medical service of the dispensaries, regarding availability of drugs, regarding doctor-patient relation, but when different patient service related factors were taken into account, overall percentage of satisfied beneficiaries was much less. A specific recommendation relates to the need to encourage the staff to treat patients with courtesy and respect and patientcentered quality assurance. Patients should not be expected to be grateful for whatever is done to/for them. Another specific recommendation is for CGHS to review the working arrangements and procedures at the different service delivery stations. The fact that some patients expressed dissatisfaction with the services indicates that CGHS needs to do more in the drive towards improving service stations in order to improve efficiency, minimize patient waiting times and provide for patient comfort.

The overall recommendation is that CGHS should strive to maintain the standard it has in order to keep patients satisfied with the services they receive. As a major health security scheme, CGHS is the final destination for many patients. CGHS should be equipped to provide the best medical care and the most highly trained health professionals should be provided to it. The patients who come to CGHS should be able to experience it as such.

\section{Acknowledgement}

Sincere gratitude to Prof.Ranadeb Biswas \& Prof. A.Dasgupta, Faculty, Dept of PSM,AIIH\&PH, Kolkata for their valuable contribution towards validation of questionnaire of this study.

\section{References}

[1] Haldar D, Sarkar A.P, Bisoi S, Mondal P :Assessment of client's perception in terms of satisfaction and service utilization in the central government health scheme dispensary at Kolkata. Indian J Commun Med 33:121-6,2008 .

[2] Roberts J.G and Tugwell P ; Comparison of questionnaires determining patient satisfaction with medical care. Health Serv Res. 22(5): 637-654,1987 December.

[3] Prasad B, Gupta VM. A qualitative assessment of antenatal care provided by auxiliary nurse midwives. Indian J Public Health 43: 140-3. 1999.

[4] CGHS Compendium, www.mohfw.nic.in/cghs.htm,(accessed on $15^{\text {th }}$ March,2008)

[5] Luthans - F, Organizational behavior (Mcgraw Hill Series in management,5 edition ,1989).

[6] Khandalwal, A, Human Resources Development (Oxford and IBH New Delhi,1988)

[7] Srivastava R.K. Assessment of Utilization of RCH Services and Client Satisfaction at different level of Health Facilities in Varanasi District. Indian J Public Health 53(3):183-189,2009 July- Sept.

[8] Akoijam BS, Konjengbam S, Bishwalata R, Singh TA: Patients' satisfaction with hospital care in a referral institute in Manipur. Indian J Public Health 51(4):240-3, 2007 Oct-Dec.

[9] Mahapatra P, Srilatha. S, Sridhar.P; A Patient Satisfaction Survey in Public Hospitals .Journal of the Academy of Hospital Administration: Vol. 13, No. 2 (2001-07 - 2001-12).

[10] Kumari R. Study on Patient Satisfaction in the Government Allopathic Health Facilities of Lucknow District. India Indian Journal of Community Medicine Vol 34: Issue 1, January 2009.

[11] Oljira L, Gebree-Selassie S. Satisfaction with outpatient health services at Jimma Hospital, SouthWest Ethiopia; Ethiopia J.Health Dev 15(3):179-84, 2001.

[12] Islam Md Ziaul, Jabbar Md Abdul :Patients' Satisfaction of Health Care Services Provided at Out Patient Department of Dhaka Medical College Hospital ; Ibrahim Medical College Journal, Vol 2, No 2 (2008).

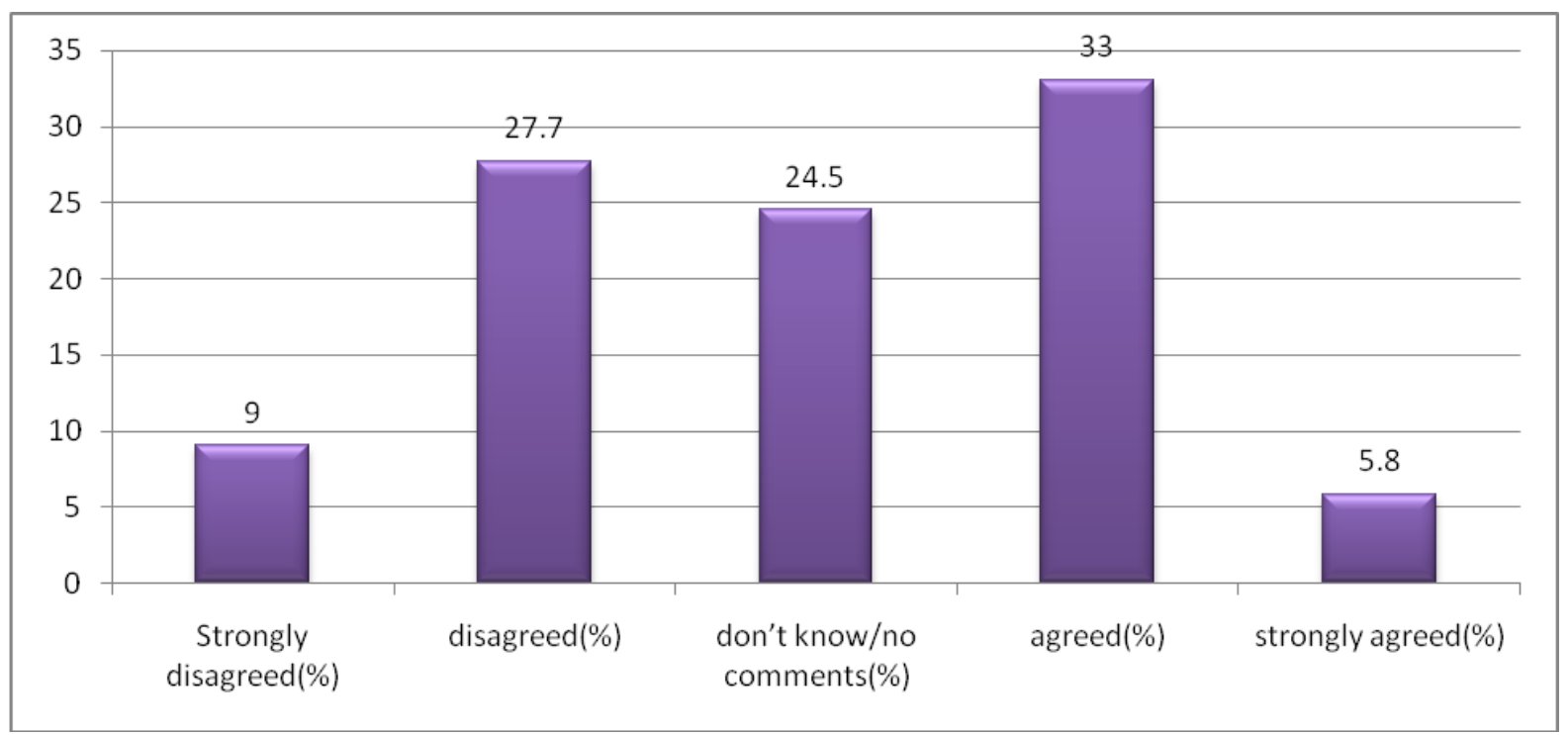

Figure 1: Responses of the patients regarding the quality of laboratory services being unsatisfactory. $(n=412)$ 


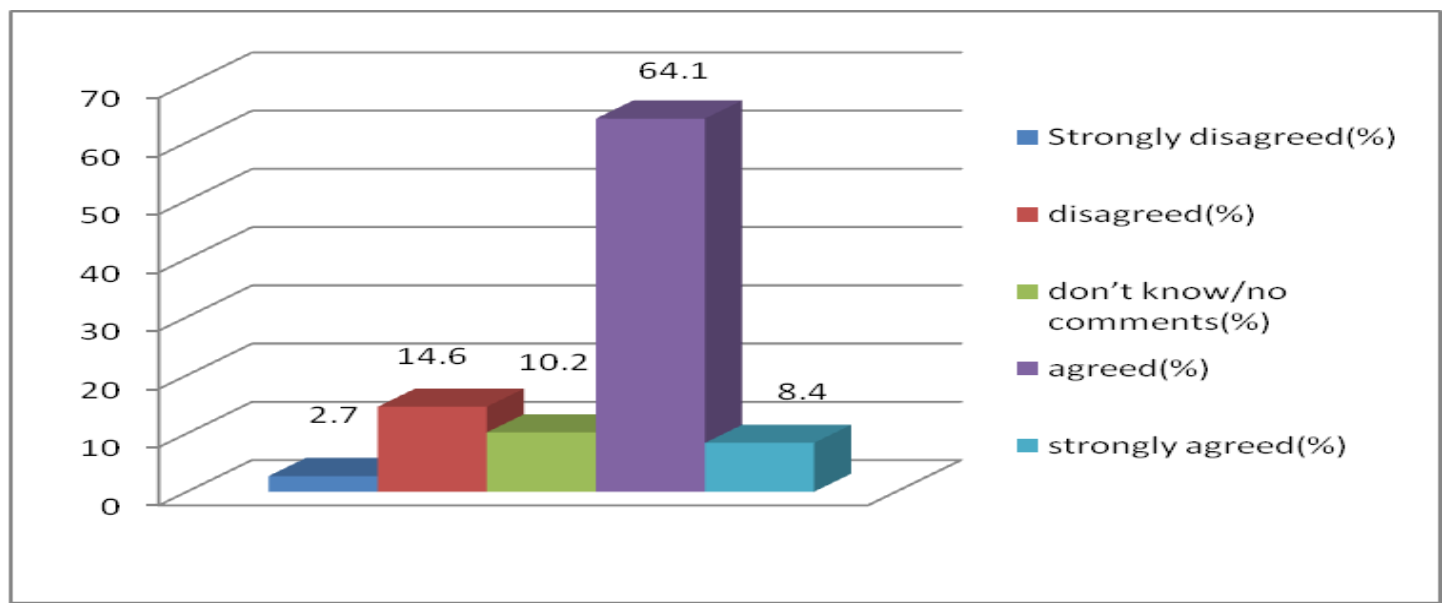

Figure 2 : Responses of the patients regarding the doctors being attentive and $\operatorname{sympathetic}(n=412)$

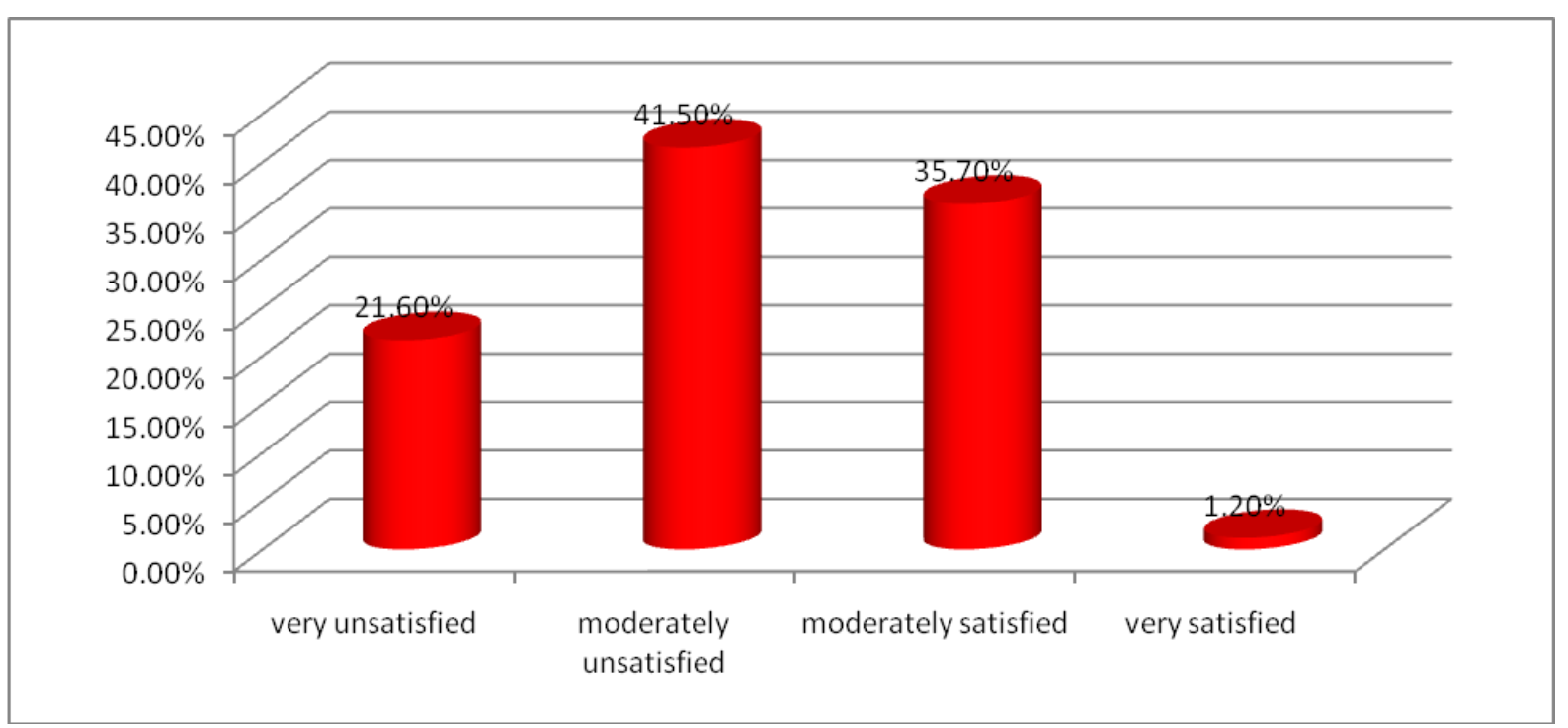

Figure 3 : Bar diagram showing the distribution of the respondents according to the level of satisfaction determined on the basis of $z$-scores arranged in quartiles. $(n=412)$.

Table-1 : Responses of the beneficiaries regarding the quality of health care services provided. $(n=412)$

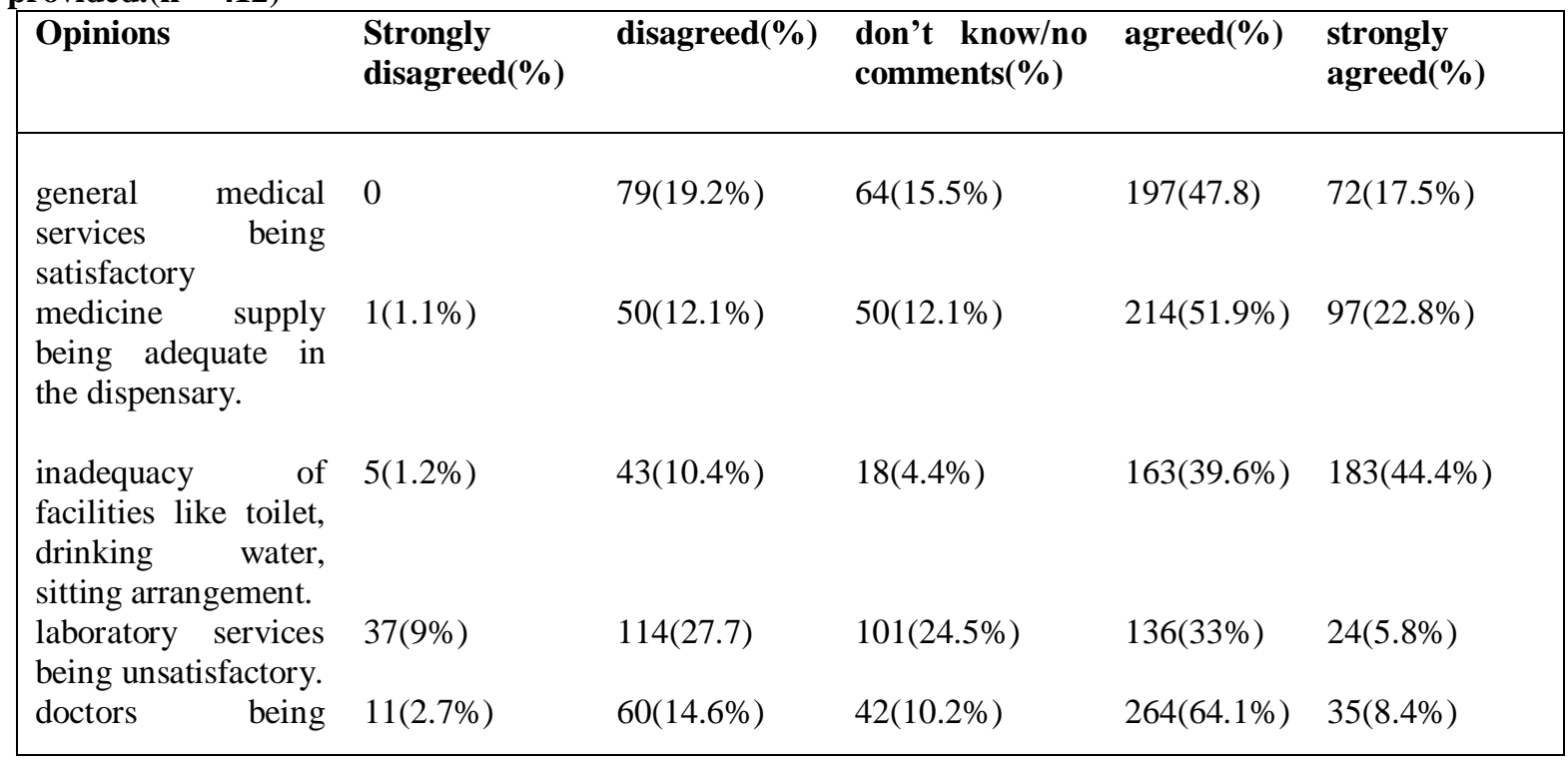




\begin{tabular}{|c|c|c|c|c|c|}
\hline $\begin{array}{lr}\text { attentive } & \text { and } \\
\text { sympathetic } & \\
\text { doctors } & \text { being } \\
\text { punctual } & \text { in } \\
\text { maintaining } & \text { outdoor } \\
\text { activities. } & \end{array}$ & $21(5.1 \%)$ & $157(38.1 \%)$ & $42(10.2 \%)$ & $139(33.7 \%)$ & $53(12.9 \%)$ \\
\hline $\begin{array}{l}\text { CGHS dispensary } \\
\text { being located near to } \\
\text { his/her house. }\end{array}$ & $53(12.9 \%)$ & $163(39.6 \%)$ & $19(4.6 \%)$ & $145(35.2 \%)$ & $32(7.7 \%)$ \\
\hline $\begin{array}{l}\text { overcrowding being } \\
\text { a problem in the } \\
\text { dispensary. }\end{array}$ & $5(1.2 \%)$ & $17(4.1 \%)$ & $26(6.3 \%)$ & $268(65 \%)$ & $96(23.4 \%)$ \\
\hline $\begin{array}{l}\text { the number of } \\
\text { doctors being } \\
\text { inadequate }\end{array}$ & $5(1.2 \%)$ & $79(19.2 \%)$ & $45(10.9 \%)$ & $202(49 \%)$ & $81(19.7 \%)$ \\
\hline $\begin{array}{l}\text { the number of } \\
\text { outdoor hours being } \\
\text { inadequate. }\end{array}$ & $5(1.2 \%)$ & $99(24 \%)$ & $83(20.1 \%)$ & $153(37.1 \%)$ & $72(17.6 \%)$ \\
\hline
\end{tabular}

Table-2: The distribution of the respondents according to the level of satisfaction determined on the basis of $z$-scores arranged in quartiles. $(n=412)$

\begin{tabular}{|lcc|}
\hline Level of satisfaction & Number of respondents & \% of respondents \\
\hline very unsatisfied & 89 & $21.6 \%$ \\
& & $41.5 \%$ \\
moderately unsatisfied(Q1) & 171 & $35.7 \%$ \\
moderately satisfied(Q2) & 147 & $1.2 \%$ \\
very satisfied (Q3) & 5 & $100 \%$ \\
total & 412 & \\
\hline
\end{tabular}

Table-3: Distribution of the level of satisfaction according to different attributes of the participants(n =412)

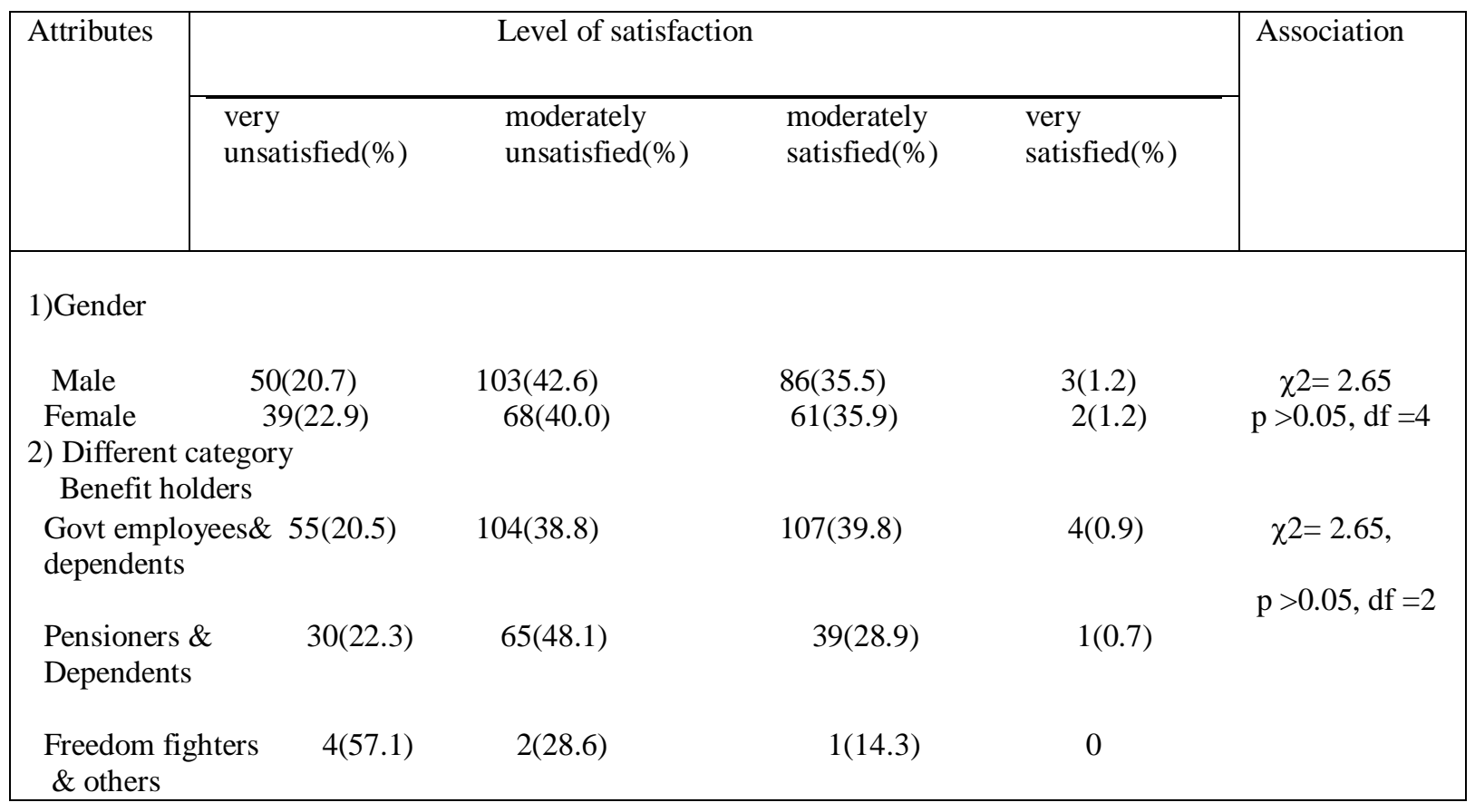




\begin{tabular}{|c|c|c|c|c|c|}
\hline \multicolumn{6}{|l|}{$\&$ dependents } \\
\hline \multicolumn{6}{|l|}{ 3)Per capita income } \\
\hline$\leq$ Rs.3000 pci & $35(26.72)$ & $63(48.1)$ & $33(25.18)$ & 0 & $\chi 2=12.83$ \\
\hline$\leq$ Rs. 6000 pci & $34(22.52)$ & $57(37.75)$ & $58(38.41)$ & $2(1.32)$ & $\mathrm{p} \leq 0.05, \mathrm{df}=3$ \\
\hline$\leq$ Rs. 9000 pci & $13(16.88)$ & $27(35.06)$ & $34(44.15)$ & $3(3.91)$ & \\
\hline$\geq$ Rs. 9000 pci & $7(13.21)$ & $24(45.28)$ & $22(41.51)$ & 0 & \\
\hline \multicolumn{6}{|l|}{ 4)Age groups } \\
\hline$\leq 20 \mathrm{yrs}$ & $21(30.9)$ & $25(36.8)$ & $21(30.9)$ & $1(1.4)$ & $\chi 2=5.54$, \\
\hline$\leq 40 \mathrm{yrs}$ & $11(11.3)$ & $46(47.4)$ & $38(39.2)$ & $2(2.1)$ & $\mathrm{p}>0.05, \mathrm{df}=3$ \\
\hline$\leq 60 \mathrm{yrs}$ & $25(23.1)$ & $36(33.3)$ & $46(42.7)$ & $1(0.9)$ & \\
\hline$>60 \mathrm{yrs}$ & $32(23.0)$ & $64(46.1)$ & $42(30.2)$ & $1(0.7)$ & \\
\hline
\end{tabular}

